\title{
Laser speckles
}

\section{A bibliography: 1981-1982}

K. Singh, Arvind Kumar

Indian Institute of Technology, Delhi, Hauz Khas, New Delhi 110016, India.

There is a rapidly growing interest in speckles and a large number of papers have been written on the subject. It could be seen that the activity in the field has been continued without any signs of slowing down. As a part of our programme of research on speckles, bibliographies [1]-[5] have been prepared and published from time to time. This bibliography is the result of an attempt to gather references to all publications relevant to speckles which appeared in book-form, in academic journals, and in conference proceedings during the years 1981 and 1982. It does not intend to be a general introduction to the literature of speckles. The purpose is to collect and to disseminate as many publication citations of interest as become the focus attention of the authors. It is hoped that the present bibliography will be as popular and useful to researchers as its earlier parts. Any suggestions regarding its completion would be most welcome.

The authors express sincere appreciation to Professor J. C. Dainty, Dr C. S. Vikram, Dr A. K. Gupta and Dr K. Dilip for their help in the compilation of this bibliography. Thanks are also due to many researchers in the area, for pointing out that the series has been of immense help to them.

[1] K. Singh, Laser Speckles; Statistics, Removal and Applications: A Bibliography, Atti. Fond. G. Ronchi 27 (1972), 197-203.

[2] K. Singh, Laser Speckles - A Bibliography: 1974-75, J. Optics (India) 9 (1980), 86-95.

[3] K. Singh, Laser Speckles - A Bibliography: 1976-78, J. Opt. (India) 8 (1979), 51-69.

[4] K. Singh, Laser Speckles - A Bibliography: 1979, J. Opt. (India) 10 (1981), $17-23$.

[5] K. Singh, Laser Speckles - A Bibliography: 1980, J. Opt. (India) 10 (1981), 61-67.

1981

1. M. Abbattista, L. Abbattista, N. Rodriguez, R. Torroba, L. Zerbino, M. Gallardo, M. Garavaglia, Application of Vertical Brackets in Orthodontic Treatments: A Laser Speckle Study, [in] Lasers and Applications, Eds. W. O. N. Guimaraes et. al., Springer-Verlag, 1981, pp. 278-285.

2. C. Aime, S. Kadiri, F. Martin, G. Ricort, Temporal Autocorrelation Functions of Solar Speckle Pattern, Opt. Commun. 39 (1981), 287-292.

3. I. M. Allison, A. E. EnNos, Evaluating Two-Dimensional Strain Distributions 
Using Speckle Pattern Photography and Photo-Elasticity, [in] Optical Methods in Mechanics of Solids, [Ed.] A. Lagarde, Sijthoff and Noordhoff, 1981, pp. 323-330.

4. G. APrIL, Ph. D. Thesis, Univ. Laval, Quebec (Canada) 1981.

5. H. H. Arsenault, M. Denis, Integral Expression for Transforming Signal-Dependent Noise into Signal-Independent Noise, Opt. Lett. 6 (1981), 210-212.

6. T. Asakura, N. TAKaI, Dynamic Laser Speckles and their Application to Velocity Measurements of the Diffuse Object, Appl. Phys. 25 (1981), 179-194.

7. R. D. Bahuguna, K. K. Gupta, K. Singh, Contrast for Unidirectionally Integrated Speckles Formed by Light of Finite Bandwidth, Opt. Acta 28 (1981), 489-494.

8. M. N. Bailangadi, F. P. Chiang, General Analysis of the Projection Speckle Method, Appl. Opt. 20 (1981), A90.

9. P. L. BAKer et al., Speckle Pattern Photographic Measurements of Photoplasmic Streaming Velocities, Atti. Fond. G. Ronchi 36 (1981), 281-291.

10. H. P. Baltes, A. S. Glass, K. M. JaUCH, Multiplexing of Coherence by Beam-Splitters, Opt. Acta 28 (1981), 873-876.

11. H. P. Baltes, H. A. Ferwerda, A. S. Glass, B. Steinle, Retrieval of Structural Information from the Far-Zone Intensity and Coherence of Scattered Radiation, Opt. Acta 28 (1981), 11-28.

12. R. BARAKAT, Direct Derivation of Intensity and Phase Statistics of Speckle Produced by a Weak Scatterer from the Random Sinusoid Model, J. Opt. Soc. Am. 71 (1981), 86-90.

13. R. BARAKAT, P. Nisenson, Influence of the Wave-Front Correlation Function and Deterministic Wave-Front Aberrations on the Speckle Image-Reconstruction Problem in the High-Light-Level Regime, J. Opt. Soc. Am. 71 (1981), 1390-1402.

14. N. B. Baranova, B. Ya. Zeldovich, Dislocations of the Wavefront Surface and Zeros of the Amplitude, Sov. Phys. JETP 53 (1981), 925-929.

15. N. B. BaRAnova et al., Dislocations of the Wavefront of a Speckle-Inhomogeneous Field (Theory and Experiment), JETP Lett. 33 (1981), 195-198.

16. H. BARTELT, K. H. BRENNER, The Wigner Distribution Function Experiments and Applications, [in] Optics in Four-Dimensions, [Eds.] M. A. Machado, L. Narducii, Am. Inst. Phys. Conf. Ser. 1981.

17. H. Bartelt, Analytic Functions in Optics, Forschungsberichte, Physikalisches Institut, Universität Erlangen-Nurnberg (Germany), 1981.

18. L. P. BAYVEL, A. R. JoNeS, Electromagnetic Scattering and Its Applications, Applied Science Publishers, U. K., 1981.

19. D. Bonneau, L. Koechlin, J. L. Oneto, F. Vakili, Stellar Diameter Measurements by Two-Telescope Interferometry in Optical Wavelengths, Astron. Astrophys. 103 (1981), 28-34.

20. E. Bowell, B. L. Morgan, K. Lumme, J. C. Dainty, H. A. Vine, M. Poutanen, Speckle Interferometric Observations of Ceres, Vesta, Hebe and Victoria, Bull. Am. Astron. Soc. 13 (1981); 719.

21. B. J. Brames and J. C. DainTy, Method for Determining Object Intensity Distributions in Stellar Interferometry, J. Opt. Soc. Am. 71 (1981), 1542-1545. 
22. Yu. M. BRUCK, L. G. SoDIN, Reconstruction of Images Scattered in Inhomogeneous Medium, Rep. No. 170 (1981), Acad. Sci. Ukrainian SSR., Inst. Radiophys. and Electron, Kharkov.

23. G. C. BRUNNHOEFFER III, Full Field State-of-Stress Determination for Plates Using Speckle Interferometry, SESA Spring 1981 Meeting, Michigan 1981.

24. C. J. BUdhIRAJA, S. C. SoM, Improvement of Image Quality in Holographic Microscopy, Appl. Opt. 20 (1981), 1848-1853.

25. W. H. CARTER, E. Wolf, Correlation Theory of Wavefields Generated by Fluctuating Three-Dimensional, Primary, Scalar Sources. I General Theory, Opt. Acta 28 (1981), 227-244.

26. W. H. Carter, E. Wolf, Correlation Theory of Wavefields Generated by Fluctuating, Three-Dimensional, Scalar Sources. II. Radiation from Isotropic Model Sources, Opt. Acta 28 (1981), 245-259.

27. Y. J. Chao, M. A. Sutton, C. E. TAYlor, A Simple Tool for Speckle Shearing Interferometry, SESA 1981 Spring Meeting, Michigan (USA).

28. Y. J. ChaO, M. A. Sutton, C. E. TAYlor, A Simple Tool for Speckle-Shearing Interferometry, Exp. Mech. 21 (1981), 436-440.

29. J. C. Charmet, Holographic Interferometry and Speckle Photography, [in] Optical Methods in Mechanics of Solids, [Ed.] A. Lagarde, Sijthoff and Noordhoff, 1981, pp. 315-321.

30. F. P. Chiang, K.-C. Chin, W.-B. Chang, Time-Average Laser Specklegram of Plate Vibration Using Multiaperture Recording, Appl. Opt. 20 (1981), $1123-1124$.

31. F. P. Chiang, A. Asund, White Light Speckle Methods with Tandem Plates for 3-D Displacement and Deformation Measurement on Curved Surfaces, Appl. Opt. 20 (1981), 2167-2169.

32. F. P. Chiang, B. Ranganayakamma, A New Three-Dimensional Strain Analysis Technique Using Embedded Scattered Planes and Laser Speckles, [in] Optical Methods in Mechanics of Solids, [Ed.] A. Lagarde, Sijthoff and Noordhoff, 1981, pp. 335-336.

33. C. H. Chien, W. F. Swinson, J. L. Turner, W. F. Ransom, Extending the Laser Specklegram Technique to Strain Analysis of Rotating Components, SESA Spring 1981 Meeting, Michigan (USA).

34. J. ChRistou, Imaging of Star Clusters From Speckle Interferometry, Opt. Commun. 37 (1981), 331-334.

35. J. H. Churnside, H. T. YuRA, Velocity Measurement Using Laser Speckle Statistics, Appl. Opt. 20 (1981), 3539-3541.

36. B. Daino, G. DeMarchis, S. Piazzolla, Modal Noise in Optical Fibers in the Presence of Model Correlation, Opt. Commun. 38 (1981), 340-344.

37. J. C. Dainty, D. R. Hennings, K. A. O'Donnell, Space-Time Correlation of Stellar Speckle Patterns, J. Opt. Soc. Am. 71 (1981), 490L-492L.

38. R. DANDliker, J. F. Willemin, Measuring Microvibrations by Heterodyne Speckle Interferometry, Opt. Lett. 6 (1981), 165-167.

39. R. DANDliker, Holographic Interferometry and Speckle Photography for 
Strain Measurement: A Comparison, [in] Optical Methods in Mechanics of Solids, [Ed.] A. Lagarde, Sijthoff and Noordhoff, 1981, pp. 343-344.

40. M. Deka, S. P. Almeida, H. FujI, Root-Mean-Square Difference between the Intensities of non-Gaussian Speckle at Two Different Wavelengths, J. Opt. Soc. Am. 71 (1981), 155-163.

41. R. Desailly, C. Froehly, Whole-Field Method in Three-Dimensional Photoelasticimetry: Improvement in Contrast Fringes, [in] Optical Methods in Mechanics of Solids, [Ed.] A. Lagarde, Sijthoff and Noordhoff, 1981, pp. 345-357.

42. J. EBBENI, Holography in Solid Mechanics, [in] Optical Methods in Mechanics of Solids, [Ed.] A. Lagarde, Sijthoff and Noordhoff, 1981, pp. 195-221.

43. A. E. EnNos, M. S. VIRDEe, Practical Evaluation in the Dilatation of Large Hydraulic Cylinders under Load, Using Holographic Interferometry and Speckle Photography, [in] Optical Methods in Mechanics of Solids, [Ed.] A. Lagarde, Sijthoff and Noordhoff, 1981, pp. 331-334.

44. A. E. EnNos, The Role and Limitation of Optical Methods for Deformation Analysis, SESA Spring 1981 Meeting, Michigan (USA).

45. Y. Fainman, J. Shamir, E. Lenz, Static and Dynamic Behaviour of Speckle Patterns Described by Operator Algebra, Appl. Opt. 20 (1981), 3526-3538.

46. A. F. Fercher, J. D. Briers, Flow Visualization by Means of Single-Exposure Speckle Photography, Opt. Commun. 37 (1981), 326-330.

47. A. F. FerChER, P. F. STEEGER, First-Order Statistics of Stokes Parameters in Speckle Fields, Opt. Acta 28 (1981), 443-448.

48. H. A. Ferwerda, H. P. Baltes, A. S. Glass, B. Steinle, The Importance of Coherence in Inverse Problems in Optics, Rad. Sci. 16 (1981), 1047-1051.

49. J. R. FIENUP, Image Reconstruction for Stellar Interferometry, [in] Current Trends in Optics, [Eds.] F. T. Arecchi and F. R. Aussenegg, Taylor and Francis, 1981, pp. 95-102.

50. J. R. FIENUP, Fourier Modulus Image Construction, RADC-TR-81-63; Final Tech. Report, Radar and Opt. Div., ERIM Michigan (USA), Jan. 1981.

51. J. E. Fraley, W. H. Peters, W. H. Ranson, Experimental Boundary Integral Equation Application in Speckle Interferometry, SESA Spring 1981 Meeting, Michigan (USA).

52. D. L. FRIED, Laser Eye Safety; The Implications of Ordinary Speckle Statistic and Speckled-Speckle Statistics, J. Opt. Soc. Am. 71 (1981), 914-916.

53. C. FroehLy, Speckle Phenomenon and Some of Its Applications, [in] Optical Methods in Mechanics of Solids, [Ed.] A. Lagarde, Sijthoff and Noordhoff, 1981, pp. 279-313.

54. K. GasviK, Measurements of Polarization-Dependent off-Specular Peaks of Laser Light Scattered from Rough Metal Surfaces and Dielectrics, Opt. Acta 28 (1981), 131-138.

55. M. Giglio, S. Musazzi, U. Perini, A White Light Speckle Schlieren Technique, Opt. Commun. 36 (1981), 117-120.

56. M. Giglio, S. Musazzi, U. Perini, Distance Measurement from a Moving Object Based on Speckle Velocity Detection, Appl. Opt. 20 (1981), 721-722. 
57. J. W. Goodman, E. G. Rawson, Statistics of Modal Noise in Fibers; A Case of Constrained Speckle, Opt. Lett. 6 (1981), 324-326.

58. G. K. GraU, Optische Nachrichtentechnik, Springer-Verlag, 1981, pp. 227-235.

59. W. O. N. Guimares, C. T. Lin, A. Mooradian, [Eds.] Lasers and Applications, Springer-Verlag், 1981.

60. M. A. Hamed, W. F. Ransom, J. Schaeffel, W. F. Swinson, Theoretical Properties of Acoustical Speckle Interferometry, SESA Spring 1981 Meeting, Michigan (USA).

61. E. K. Hege, E. N. Hubbard, P. A. Strittmatter, S. P. Worden, Speckle Interferometry Observations of the Triple QSO PG 1115+08, Astrophys. Jour. 248 (1981), L1-L3.

62. J. HoloubeK, [in] Materials of the Microsymposium Polymer Composits, Sofia, Bulgaria (1981).

63. J. F. Holmes, V. S. RaO, Gudimetla, Variance of Intensity for a Discrete-Spectrum, Polychromatic Speckle Field after Propagation through the Turbulent Atmosphere, J. Opt. Soc. Am. 71 (1981), 1176-1179.

64. R. R. Howell, D. W. McCarthy, F. J. Low, One-Dimensional Infrared Speckle Interferometry, Astrophys. Jour. 251 (1981), L21-L25.

65. A. M. J. HuISER, H. P. BALTES, Electromagnetic Scattering by Perfectly Conducting Rough Surfaces: Facet Model, Opt. Commun. 40 (1981), 1-4.

66. Y. Y. Hung, J. D. Hovanesian, L. WANG, Isopachic Generation in Photoelastic Coatings by Speckle Interferometry, SESA Spring 1981 Meeting, Michigan (USA).

67. Y. Y. HUNG, Acoustical Interferometry with Young's Fringes, SESA Spring 1981 Meeting, Michigan (USA).

68. M. ImAI, Modal Interference of Laser Light Emitted from an Optical Fiber, Radio Sci. 16 (1981), 555-561.

69. M. ImaI, M. Koseki, Y. OHTSUKa, Light Scattering from a Glass Thin-Film Optical Waveguide, J. Appl. Phys. 52 (1981), 6506-6508.

70. К. Ітон, Y. ОнтsuKA, Interferometric Image Reconstruction through the Turbulent Atmosphere, Appl. Opt. 20 (1981), 4239-4244.

71. К. Ітон, Y. ОнтsuкA, Spatial Coherence Measurements through Turbulent Atmosphere Using a Computer Aided Interferometer, Opt. Commun. 36 (1981), 250-254.

72. T. IwaI, N. TAKaI, T. Asakura, The Autocorrelation Function of the Speckle Intensity Fluctuation Integrated Spatially by a Detecting Aperture of Finite Size, Opt. Acta 28 (1981), 1425-1437.

73. T. Imai, N. TaKaI, T. Asakura, Simultaneous Magnitude and Direction Measurements of a Diffuse Object's Velocity Using the Rotating Directional Detecting Aperture in a Laser Speckle Zero-Crossing Method, Opt. Acta 28 (1981), 857-870.

74. P. JACQUOT, P. K. RASTOGI, Influence of Out-of-Plane Deformation and its Elimination in White Light Speckle Photography, Opt. Lasers Eng. 2 (1981), 33-55. 
75. G. K. JaI Singh, F. P. ChiAng, Contouring by Laser Speckle, Appl. Opt. 20 (1981), 3385.

76. E. Jakeman, A Simple Multiscale Scattering Model, Opt. Acta 28 (1981), 435-441.

77. E. Jakeman, J. G. McWhirter, Non-Gaussian Scattering by a Random Phase Screen, Appl. Phys. B26 (1981), 125-131.

78. K. M. JAUCH, H. P. BALTES, Coherence of Radiation Scattered by Gratings Covered by a Diffuser; Experimental Evidence, Opt. Acta 28 (1981), 1013-1015.

79. B. JEAN, M. L. RoBlin, Etude du chromatisme d'un systeme optique par photographie "Speckle", Opt. Commun. 37 (1981), 248-252.

80. R. JONES, C. Wykes, General Parameters for the Design and Optimization of Electronic Speckle Pattern Interferometers, Opt. Acta 28 (1981), 949-972.

81. S. KadiRI, C. Aime, G. Ricort, One-Dimensional Astronomical Speckle Interferometry: Study of the Lens-Atmosphere Modulation Transfer Function Obtained with Rectangular Aperture by Statistical Analysis of the Speckle Pattern, J. Opt. (Paris) 12 (1981), 143-151.

82. G. H. Kaufmann, Numerical Processing of Speckle Photography Data by Fourier Transform, Appl. Opt. 20 (1981), 4277-4280.

83. B. S. Kawasaki, K. O. Hill, Y. Tremblay, Modal-Noise Generation in Biconical-Taper Couplers, Opt. Lett. 6 (1981), 499-501.

84. I. S. KLIMENKo, On the Special Features of Recording Speckle Holograms in Multimode Laser Emission, Opt. Spectrosc. 50 (1981), 513-516.

85. S. Komatsu, K. Osato, H. Ohzu, Velocity Sensitivity of Laser-Speckle Velocimeters, Opt. Commun. 39 (1981), 357-361.

86. V. N. Korwar, J. R. PIERCE, Detection of Gratings and Small Features in Speckle Imagery, Appl. Opt. 20 (1981), 312-319.

87. V. N. KORWAR, J. R. PIERCE, Discrimination of Form in Images Corrupted by Speckle, Appl. Opt. 20 (1981), 320-325.

88. V. G. KUlKaRni, Speckle Reduction in Image Plane Holography, Opt. Acta 28 (1981), 1577-1581.

89. A. LABEYRIE, Interferometric Methods in Astronomy, [in] Current Trends in Optics, [Eds.] F. T. Arecchi and F. R. Aussenegg, Taylor and Francis, 1981, pp. 21-27.

90. A. LabeYRIE, [in] Proc. ESO Conf. Scientific Importance of High Angular Resolution at IR and Optical Wavelengths, Garching 1981, p. 225.

91. P. LAmy, S. Koutchmy, Infrared Imaging and Speckle Observations with a TV Camera, ESO Messenger, 1981.

92. W. Lawton, Uniqueness Results for the Phase-Retrieval Problem for Radial Functions, J. Opt. Soc. Am. 71 (1981), 1519-1522.

93. J. S. LeE, Speckle Analysis and Smoothing of Synthetic Aperture Radar Images, Comput. Graph. Image Process. 17 (1981), 24-32.

94. M. H. LeE, J. F. Holmes, Effect of the Turbulent Atmosphere on the Auto-Covariance Function for a Speckle Field Generated by a Laser Beam with Random Pointing Error, J. Opt. Soc. Am. 71 (1981), 559-565. 
95. K. LeOnhardt, B. Pfister, Optical Roughness Measurement Using the Phase Contrast Structure by Defocusing and an Incoherent Superposition of a Uniform Intensity, Optik 58 (1981), 297-319.

96. M. D. Levenson, K. M. Jonson, V. C. Hanchett, K. Chiang, Projection Photolithography by Wavefront Conjugation, J. Opt. Soc. Am. 71 (1981), 737-743.

97. J. S. Lim, H. NawaB, Techniques for Speckle Noise Removal, Opt. Eng. 20 (1981), 472-480.

98. C. J. Lin, F. P. Chiang, Laser Speckle Method for the Analysis of Steady State Vibration of Plates, J. Acoust. Soc. Am. 69 (1981), 456-459.

99. O. J. Lokberg, G. A. Slettemoen, Interferometric Comparison of Displacements by Electronic Speckle Pattern Interferometry, Appl. Opt. 20 (1981), 2630-2633.

100. O. J. LOKBERG, K. KRAKHella, Electronic Speckle Pattern Interferometry Using Optical Fibers, Opt. Commun. 38 (1981), 155-158.

101. A. R. LuXMOORE, Optical Methods for Microscopic Measurement of Displacements Around Crack Tips, [in] Optical Methods in Mechanics of Solids, [Ed.] A. Lagarde, Sijthoff and Noordhoff, 1981, 509-523.

102. J. C. MacBain, W. A. Stange, K. G. Harding, Real-Time Response of a Rotating Disk Using Image-Derotated Holographic Interferometry, Exp. Mech. 21 (1981), 34-40.

103. R. J. Maddock, M. Millodot, S. Leat, C. A. Johnson, Accommodation Responses and Refractive Error, Invest. Ophthalmol. Vis. Sci. 20 (1981), 387-391.

104. P. A. Magnin, O. T. Von Ramm, F. L. Thurstone, Delay Quantization Error in Phased Array Images, IEEE Trans. Sonics Ultrason. 28 (1981), 305-310.

105. L. V. Mastsievich, P. KH. Pruss, Determination of the Modulation Transfer Function of Photographic Materials by Means of a Random Structure, Sov. J. Opt. Tech. 48 (1981), 62-65.

106. H. A. MCAlister, E. M. HendRY, Binary Stars Unresolved by Speckle Interferometry, 2, Publ. Astron. Soc. Pac. 93 (1981), 221-225.

107. P. Melman, W. J. Carlsen, Interferometric Measurement of Time-Varying Longitudinal Cavity Modes in GaAs Diode Lasers, Appl. Opt. 20 (1981), 2694-2697.

108. E. Milana, F. Rasello, An Optical Method for on-Line Evaluation of Machined Surface Finishing, Opt. Acta 28 (1981), 111-123.

109. I. Moneva, M. Michailov, Average Speckle Size in Small-Angle Light Scattering from Polymer Films, Makromol. Chem., Rapid Commun. 2 (1981), 267-271.

110. K. Nakagawa, T. Asakura, Roughness Dependence of one-Dimensionally Elongated Dichromatic Speckle Patterns, Optik 59 (1981), 389-400.

111. Y. NaKayama, M. Kato, Image Quality in Holography with a PseudoRandom Diffuser, Appl. Opt. 20 (1981), 2178-2180.

112. P. Neiswander, G. A. Slettemoen, Electronic Speckle Pattern Interferometric Measurements of the Basilar Membrane in the Inner Ear, Appl. Opt. 20 (1981), 4271-4276.

113. M. Nieto-Vesperinas, N. Garcia, A Detailed Study of the Scattering of 
Scalar Waves from Random Rough Surfaces, Opt. Acta 28 (1981), 1651-1672.

114. P. Nisenson, J. APt, R. GoOdy, P. Horowitz, Radius and Limb Darkening of Titan from Speckle Imaging, Astron. Jour. 86 (1981), 1690-1693.

115. B. T. O'Connor, T. S. Huang, Application of Phase Unwrapping to Image Restoration, Comp. Graph. Image Process. 15 (1981), 25-44.

116. J. Oнтsuво, The Second-Order Statistisc of Speckle Patterns, J. Opt. (Paris) 12 (1981), 129-142.

117. K. OuchI, Statistics of Speckle in Syntethic Aperture Radar Imagery from Targets in Random Motion, Opt. Quant. Electron. 13 (1981), 165-173.

118. G. PARRY, Measurement of Atmospheric Turbulence Induced Intensity Fluctuation in a Laser Beam, Opt. Acta 28 (1981), 715-728.

119. M. S. Patterson, F. StuART Foster, D. Lee, Sidelobe and Speckle Reduction for an Eight Sector Conical Scanner, 1981 Ultrasonic Symp. (IEEE 1981), pp. 632-637.

120. J. PeřIna, R. HoRaK, On the Approximate Statistics of Integrated Speckle Patterns Due to Mixed Coherent and Diffused Light, Opt. Quant. Electron. 13 (1981), 345-347.

121. C. Perrier, An Infrared Speckle Interferometer, ESO Messenger, 1981.

122. R. L. Phillips, L. C. ANDrews, Measured Statistics of Laser-Light Scattering in Atmospheric Turbulence, J. Opt. Soc. Am. 71 (1981), 1440-1445.

123. K. PieTzSCH, Interferometry Disturbed by a Scattering Element, Optik 58 (1981), 173-192.

124. R. J. Pryputniewicz, Hand-Held Calculators in Quantitative Analysis of Specklegrams, Bull. Am. Phys. Soc. 42 (1981), 40.

125. H. J. Rabal, E. E. Sicre, N. Bolognini, M. Garavaglia, $A$ Speckle Method of Gray Level Pseudocoloring, Opt. Commun. 39 (1981), 225-227.

126. K. V. S. G. RAO, D. V. K. RAO, Investigation of the Strain Distribution in a Warped Square Plate Using Speckle Shearing Interferometry, Opt. Acta 28 (1981), 1009-1012.

127. E. G. Rawson, J. W. Goodman, Modal Noise in Multimode Fibers: Polarization Effects, Digest of Tech. Papers, Confer. on Lasers and Electro-Optics (CLEO'81), June 1981, Wash. D. C. (USA).

128. E. G. Rawson, J. W. Goodman, Modal Noise Effects in Multimode Fibers, J. Opt. Soc. Am. 71 (1981), 1576A.

129. E. RibaK, S. G. LiPSON, Complex Spatial Coherence Function: Its Measurement by Means of a Phase-Modulated Shearing Interferometer, Appl. Opt. 20 (1981), 1102-1106.

130. G. Ricort, Thesis, Univ. of Nice, France, 1981.

131. G. Ricort, C. Aime, C. RodDier, J. Borgnino, Determination of Fried's Parameter $r_{0}$ Prediction for the Observed r.m.s. Contrast in Solar Granulation, Solar Phys. 69 (1981), 223-231.

132. F. RoDDIER, The Effects of Atmospheric Turbulence in Optical Astronomy, [in] Progress in Optics, Vol. 19 [Ed.] E. Wolf, North Holland 1981, pp. 281-376.

133. B. Ruffing, Einflu $\beta$ von Teilkohärenter Beleuchtung bei der Speckle Korrelation, Studienarbeit am Institut für Mess, und Regelungstechnik Universität (TH), Karlsruhe, Germany, 1981. 
134. J. SaijonmaA, S. J. Halme, Reduction of Modal Noise by Using Reduced Spot Excitation, Appl. Opt. 20 (1981), 4302-4306.

135. R. A. SCOTt, P. L. M. ThOR PE, B. M. WATRASIEWICZ, Isometric Projections for Vibration Phase and Amplitude by the Use of Electronic Speckle Pattern Interferometry, SESA Spring 1981 Meeting, Michigan (USA).

136. J. H. Shapiro, B. A. CAPron, R. C. HARney, Imaging and Target Detection with a Heterodyne-Reception Optical Radar, Appl. Opt. 20 (1981), 3292-3313.

137. L. SicA, Fourier Space Separability in Space-Variant Imaging, J. Opt. Soc. Am. 71 (1981), 493-495.

138. L. SiCA, Image-Sharpness Criterion for Space-Variant Imaging, J. Opt. Soc. Am. 71 (1981), 1172-1175.

139. E. E. Sicre, N. Bolognini, H. J. Rabal, M. Gara Vaglia, Color Storage and Image Processing through Young's Fringes Modulated Speckle, [in] Optics in Four-Dimensions, [Eds.] M. A. Machado and L. M. Narducci, Am. Inst. Phys. 1981.

140. P. G. Simpkins, T. D. DudDerar, Convection in Rectangular Cavities with Differentially Heated End Walls, J. Fluid Mech. 110 (1981), 433-456.

141. K. SingH, Laser Speckles; A Bibliography: 1979, J. Opt. (India) 10 (1981), $17-23$.

142. K. SinGH, Bibliography on Speckles: 1980, J. Opt. (India) 10 (1981), 61-67.

143. G. A. Slettemoen, First-Order Statistics of Displayed Speckle Patterns in Electronic Speckle Pattern Interferometry, J. Opt. Soc. Am. 71 (1981), 474-482.

144. G. A. Slettemoen, O. J. LoKberg, Speckle Reference ESPI: In Practice, Appl. Opt. 20 (1981), 3467-3469.

145. M. Spajer, P. K. Rastogi, J. Monneret, In-Plane Displacement and Strain Measurement by Speckle Interferometry and Moire Derivation, Appl. Opt. 20 (1981), 3392-3401.

146. C. T. Stansberg, Surface Roughness Dependence of the First-Order Statistics of Polychromatic Speckle Patterns, Opt. Acta 28 (1981), 471-488.

147. C. T. Stansberg, On the First-Order Probability Density Function of Integrated Laser Speckle, Opt. Acta 28 (1981), 917-932.

148. K. A. SteTSON, Strain Measurement on a Rough Surfaces by Optical Heterodyning, SESA Spring 1981 Meeting, Michigan (USA).

149. K. A. STETSON, The Use of Heterodyne Speckle Photogrammetry to Measure High-Temperature Strain Distributions, Proc. SPIE 370 (1981).

150. C. C. Sung, J. D. Stettler, T. L. Kuo, Statistical Properties of Light Reflected from a Moderately Rough Surface Scanned through a Finite Size Aperture, Appl. Opt. 20 (1981), 963-967.

151. M. A. TAFralian, C. E. TAYlor, Stress Wave and Propagating Crack Studies Using Speckle Photography with a Pulsed Ruby Laser, [in] Optical Methods in Mechanics of Solids, [Ed.] A. Lagarde, Sijthoff and Noordhoff, 1981, pp. 337-341.

152. A. M. TAI, et al., Imaging through Scattering Media by Interferometric Techniques, Appl. Opt. 20 (1981), 2484-2492.

153. A. M. TAI, C. C. Aleksoff, Transmission of Incoherent Images through Scattering Media with a Grating Interferometer, Opt. Lett. 6 (1981), 308-310.

154. N. TAKaI, T. IwaI, T. AsaKura, Laser Speckle Velocimeter Using a Ze- 
ro-Crossing Technique for Spatially Integrated Intensity Fluctuation, Opt. Eng. 20 (1981), 320-324.

155. N. Takai, T. Imai, T. Asakura, An Effect of Curvature of Rotating Diffuse Objects on the Dynamics of Speckles Produced in the Diffraction Field, Appl. Phys.

B 26 (1981), 185-192.

156. H. F. TAYLOR, Noise in Single-Mode Fiber Optic Systems, J. Opt. Soc. Am. 71 (1981), 1576A.

157. H. J. Tiziani, J. Klenk, Vibration Analysis by Speckle Techniques in Real Time, Appl. Opt. 20 (1981), 1467-1470.

158. Y. Tremblay, B. S. Kawasaki, K. O. Hill, Modal Noise in Optical Fibers: Open and Closed Speckle Pattern Regimes, Appl. Opt. 20 (1981), 1652-1655.

159. B. J. UsCinski, H. G. Booker, M. Marians, Intensity Fluctuations Due to a Deep Phase Screen with a Power-Law Spectrum, Proc. Roy. Soc. (London) A 374 (1981), 503-530.

160. J. Uozumi, T. Asakura, First-Order Intensity and Phase Statistics of Gaussian Speckle Produced in the Diffraction Region, Appl. Opt. 20 (1981), 1454-1466.

161. J. Uozumi, T. Asakura, The First-Order Statistics of Partially Developed Non-Gaussian Speckle Patterns, J. Opt. (Paris) 12 (1981), 177-186.

162. F. Vakili, D. Bonneau, L. Koechisn, High Angular Resolution Ohservation of Single and Close Binary Stars with the CERGA Interferometer, [in] Proc. ESO Conference on Scientific Importance of High Angular Resolution at Infrared and Optical Wavelengths, Garching, 24-27 March 1981, pp. 399-404.

163. C. S. Vikram, K. Vedam, Direct Observation of Laser Speckles for Real-Time Analysis of Lateral Motions, Opt. Lett. 6 (1981), 511-513.

164. C. S. Vikram, K. Vedam, Speckle Photography of Lateral Sinusoidal Vibrations: Error Due to Varying Halo Intensity, Appl. Opt. 20 (1981), 3388-3391.

165. T. V. Vorburger, E. C. Teague, Optical Techniques for on-Line Measurement of Surface Topography, Precision Eng. (1981), 61-83.

166. J. G. WALKER, Object Reconstruction from Turbulence-Degraded Images, Opt. Acta 28 (1981), 1017-1019.

167. J. G. WALKER, Statistical Accuracy in Stellar Speckle Interferometry at Law Light Levels, Opt. Acta 28 (1981), 885-905.

168. J. M. Webster, J. K. Hepworth, C. Forno, Strain in Transition Joints Measured by High-Resolution Moire Photography, Exp. Mech. 21 (1981), 195-199.

169. A. R. Weeks, T. M. Toor, L. A. Bizzeli, D. M. Kotick, M. A. Robitaille, J. P. Klages, Modal Noise in Multimode Fibers Due to Temperature Variations and Vibrations, J. Opt. Sóc. Am. 71 (1981), 1576A.

170. G. WeIGelt, Interferometric Methods in Optical Astronomy, [in] Current Trends in Optics, [Eds.] F. T. Arecchi and F. R. Ausenegg, Taylor and Francis 1981, pp. 28-29.

171. G. Weigelt, Speckle Interferometry, Speckle Holography, Speckle Spectroscopy, and Reconstruction Images from ST Data, [in] Proc. ESO Conf. on Scientific Importance of High Angular Resolution at IR and Optical Wavelengths, Garching 1981, p. 94. 
172. W. T. Welford, Book Review: Application of Speckle Phenomena (SPIE Proc. 243 (1980), [Ed.] W. H. Carter), Opt. Acta 28 (1981), 1035.

173. C. WYKes et al., Fringe Contrast in Electronic Speckle Pattern Interferometry, Appl. Opt. 20 (1981), A50.

174. I. Yamaguchi, Speckle Displacement and Decorrelation in the Diffraction and Image Fields for Small Object Deformation, Opt. Acta 28 (1981), 1359-1376.

175. I. YAMAGUCHI, Measurement of Radii of Wavefront Curvature by Electronic Speckle Correlation, Kogaku 10 (1981) 460 (50)-464 (54).

176. I. Yamaguchi, A Laser-Speckle Strain Gauge, J. Phys. E: Sci. Instrum. 14 (1981), 1270-1273.

177. F. T. S. Yu, P. H. Ruterbusch, G. Gheen, G. Gerhart, White Light Processing of Multiplexed Speckle Interferogram, J. Opt. Soc. Am. 71 (1981), 1610A.

1982

1. A. K. Aggarwal, Chandra Shakher, Delinking of Spurious Translation in HI Using Speckle Correlation Technique, J. Opt. (Paris) 13 (1982), 325-330.

2. W. Albrecht et al., Optical Digital High-Speed Transmission: General Considerations and Experimental Results, IEEE Trans. QE-18 (1982), 1547.

3. A. G. Apostolidis, J. SPYRIDELIS, Image Multiplexing and Color Images with Theta Modulation of the Speckle Patterns, Opt. Commun. 40 (1982), 249-253.

4. A. Asundi, F. P. Chiang, Theory and Applications of the White Light Speckle Method for Strain Analysis, Opt. Eng. 21 (1982), 570-580.

5. M. Azourt, Real-Time Correlator of Video-Images, J. Opt. (Paris) 13 (1982), 345-358.

6. W. G. Bagnuolo, Jr. The Application of Bates Algorithm to Binary Stars, Mon. Not. R. Astron. Soc. 200 (1982), 1113.

7. Y. Balega, A. Blazit, D. Bonneau, L. Koechlin, R. Foy, A. Labeyrie, The Angular Diameter of Betelgeuse, Astron. Astrophys. 115 (1982), 253-256.

8. N. BARAKAT, Interference from Two Identical Diffusers, Physica 113C (1982), $143-147$.

9. R. BARAKAT, Isotropic Random Flights: Random Number of Flights, J. Phys. A: Math. Gen. 15 (1982), 3073-3082.

10. R. BARAKAT, Speckle Intensity Due to Strong and Weak Scatterers in the Presence of Amplitude-Correlated Multipaths, Opt. Acta 29 (1982), 947-960.

11. J. H. T. BAtes et al., Subtractive Image Restoration, III. Some Practical Applications, Optik 62 (1982), 333-346.

12. J. H. T. BATES et al., Subtractive Image Restoration, II. Comparison with Multiplicative Deconvolution, Optik 62 (1982), 1-14.

13. R. H. T. BATES, W. R. FrIGHT, Towards Imaging with a Speckle Interferometric Optical Synthesis Telescope, Mon. Not. R. Astron. Soc. 198 (1982), 1017-1031.

14. R. H. T. BATES, Astronomical Speckle Imaging, Phys. Rep. 90 (1982), 203-297.

15. J. M. BeCKers, E. K. HeGE, Experiments in Differential Speckle Interferomet- 
ry, [in] Instrumentation for Astronomy with Large Optical Telescopes, [Ed.] C. M. Humphries, D. Reidel Publ. Co. 1982, pp. 199-206.

16. J. M. BECKERS, Differential Speckle Interferometry, Opt. Acta 29 (1982), 361-362.

17. B. D. Bergquist, J. N. Butters, Holographic and Laser Speckle Measurements, [in] Electro-Optics/Laser International, Brighton (UK) 1982, [Ed.] H. G. Jerrard, Butterworths 1982, pp. 307-319.

18. E. Bernabeu, J. C. Amare, M. P. Arroyo, White-Light Speckle Method of Measurement of Flow Velocity Distribution, Appl. Opt. 21 (1982), 2583-2586.

19. L. R. Bissonnette, Adaptive Optical System Referencing in the Case of Resolved Targets Illuminated through Turbulence, Appl. Opt. 21 (1982), 3998-4004.

20. G. BITZ, Verfahren zur Beshinung von Rauheitskenngroßen durch Speckle Korrelation, Doctoral Thesis; Universität (TH) Karlsruhe (Germany), 1982.

21. F. Boner, W. Shaude, Speckle Motion Due to Laser Light Scattering off non-Homogeneous Media, Opt. Commun. 40 (1982), 407-409.

22. D. Bonneau, R. Foy, A. Blazit, A. Labeyrie, The Diameter of Mira, Astron. Astrophys. 106 (1982), 235-239.

23. P. M. Boone, Use of Close Range Objective Speckles for Displacement Measurement, Opt. Eng. 21 (1982), 407-410.

24. J. D. BRIERS, A. F. FerCher, Retinal Blood-Flow Visualization by Means Laser Speckle Photography, Invest. Ophthalmol. and Visual Sci. 22 (1982), 255-259.

25. J. D. BrIERS, A. F. Fercher, Retinal Blood Flow Visualization by Means of Laser Speckle, [in] Optics in Biomedical Sciences, [Eds.] G. von Bally and P. Greguss, Springer-Verlag 1982, pp. 158-161.

26. J. D. BRIERS, A. F. FERCHER, A Laser Speckle Technique for the Visualization of Retinal Blood Flow, Proc. SPIE 369 (1982), 22-28.

27. C. Brophy, G. M. Morris, Speckle in Achromatic Transform Systems, J. Opt. Soc. Am. 72 (1982), 1743A.

28. H. Bruhn, A. FelSKe, [in] Electro-Optics/Laser International, 1982 Brighton (UK), [Ed.] H. G. Gerrard, Butterworths 1982.

29. P. J. Bryanston-Cross, J. J. Camus, P. H. Richards, Intensity Correlation Measurements on a Schlieren Image, Opt. Acta 29 (1982), 1161-1166.

30. M.-Y. CHEN, D. SHAN, Cross Slit Multiaperture Laser Speckle Interferometry, J. Opt. Soc. Am. 72 (1982), 1754A.

31. Y. C. CHIA, M. C. FU, Recent Research Activities in Experimental Mechanics in China, Exp. Mech. (1982), 171-173.

32. F. P. Chiang, C. C. KIn, Strain Determination on Curved Surfaces Using Far-Field Objective Laser Speckles, Opt.Eng. 21 (1982), 441-446.

33. F. P. Chiang, J. Adachi, R. Anastasi, J. Beatty, Subjective Laser Speckle Method and its Application to Solid Mechanics Problems, Opt. Eng. 21 (1982), 379-390.

34. F. P. Chiang, A. Asund, Perspective Effect in the White Light Speckle Method, Appl. Opt. 21 (1982), 1708-1710.

35. F. P. ChiAng, A. K. Asund, Objective White Light Speckles and their Application to Stress-Intensity Factor Determination, Opt. Lett. 7 (1982), 378-379. 
36. C. H. Chien, J. L. Turner, W. F. Swinson, W. F. Ranson, Extending the Laser-Specklegram Technique to Strain Analysis of Rotating Components, Exp. Mech. 22 (1982), 434-440.

37. L. C. Chien, J. L. Turner, J. Weathers, W. F. Swinson, Manual for Extending the Laser Specklegram Technique to Strain Analysis of Rotating Components, NASA Contractor Report 167932.

38. J. H. Churnside, Speckle from a Rotating Diffuse Object, J. Opt. Soc. Am. 72 (1982), 1464-1469.

39. W. J. Cocke, E. K. Hege, E. N. Hubbard, P. A. Strittmatter, S. P. Worden, An Image Reconstruction for Capella with the Steward Observatory/AFGL Intensified Video Speckle Interferometry System, [in] Internat. Astronom. Coll. 62, Flagstaff 1981, [Ed.] R. S. Harrington, Bull. Lowell Observ., 1982.

40. J. P. Corteggiani, J. Gay, A. Journet, Y. Rabbia, Real-Time Infrared Imaging of Stars Using Multiplex Encoding Techniques, J. Opt. (Paris) 13 (1982), 9-11.

41. M. Cottron, R. Desallly, A. Lagarde, Détermination des facteurs d'intensité de contraintes en mode mixte pour un probleme plan a partir des données des champs de granularité, Rev. Franc. Mech. (1982), 69-72.

42. B. Crosignani, P. D. Porto, Self-Phase Modulation and Modal Noise in Optical Fibers, J. Opt. Soc. Am. 72 (1982), 1553-1555.

43. J. C. DaINTY, Stellar Interferometry; A Bibliography, Inst. Opt. Univ. Rochester, Jan. 1982.

44. J. C. Dainty, B. M. Levine, B. J. Brames, K. A. O’Donnell, Measurements of the Wavelength Dependence and other Properties of Stellar Scintillation at Mauna Kea, Hawaii, Appl. Opt. 21 (1982), 1196-1200.

45. M. Dentcheva, J. Georgieva, A Possibility for Extending the Limits of Measurable Displacements by Double Exposure Speckle Photography, Opt. Commun. 40 (1982), 322-324.

46. T. D. Dudderar, P. G. Simpkins, The Development of Scattered Light Speckle Metrology, Opt. Eng. 21 (1982), 396-399.

47. T. D. Dudderar, J. A. Gilbert, Fiber-Optic Measurement of the Deformation Field on a Remote Surface Using Numerically Processed White-Light Speckle, Appl. Opt. 21 (1982), 3520-3527.

48. H. M. Dyck, R. R. Howell, Speckle Interferometry of Molecular Cloud Sources at 4.8 Microns, Astron. J. 87 (1982), 400-405.

49. E. Eichen, J. C. Wyant, Speckle Reduction in Laser Displays, J. Opt. Soc. Am. 72 (1982), 1743A.

50. J. M. Elson, C. C. SUNG, Intrinsic and Roughness Induced Absorption of Electromagnetic Radiation Incident on Optical Surfaces, Appl. Opt. 21 (1982), 1496.

51. A. E. EnNos, M. S. VIRDEE, Laser Speckle Photography as a Practical Alternative to Holographic Interferometry for Measuring Plate Deformation, Opt. Eng. 21 (1982), 478-482.

52. Y. Fainman, E. Lenz, J. Shamir, Optical Profilometer: A New Method for High Sensitivity and Wide Dynamic Range, Appl. Opt. 21 (1982), 3200-3208.

53. A. F. Fercher, H. Z. Hu, P. F. Steeger, J. D. Briers, Eye Deformation Measurement by Laser Interferometry, Opt. Acta 29 (1982), 1401-1406. 
54. A. F. Fercher, J. D. Briers, Application of Laser Speckle Methods to Retinal Blood Flow Measurement, [in] Optoelectronics in Medicine, Proc. 5th Int. Congress Lasers'81, Munich 1981, Vol. 2, [Ed.] W. Waidelich, Springer-Verlag, 1982, pp. 203-206.

55. J. R. FIENUP, Reconstruction and Synthesis Applications of an Iterative Algorithm, SPIE Proc. (1982) [Eds.] W. T. Rhodes, J. R. Fienup, B. E. A. Saleh.

56. J. R. FienuP, Phase Retrieval Algorithms: A Comparison, Appl. Opt. 21 (1982), 2758-2769.

57. W. Freude, G. Grau, Estimation of Modal Noise for Arbitrary Connectors, Fibres and Sources, Arch. Elektron. Übertragungs. 36 (1982), 91-93.

58. N. C. Gallagher, D. W. Sweeney, C. R. Christensen, G. R. Arce, P. K. Murphy, J. P. Fitch, Speckle Noise Filtering by Use of Median-Filter Root Signals, J. Opt. Soc. Am. 72 (1982), 1743A.

59. C. S. Gardner, Target Signatures for Laser Altimeters: An Analysis, Appl. Opt. 21 (1982), 448-453.

60. C. Gazanhes, E. A. Calaora, R. Condat, Acoustical Measurement of Surface Roughness Using Interferometry and Speckle Correlation, Signal Processing 4 (1982), 155-167.

61. G. R. Gerhart, P. H. Ruterbusch, White Light Image Plane Holography Using Fringe Modulated Speckle Patterns, J. Opt. Soc. Am. 72 (1982), 1825A.

62. G. R. Gerhart, P. H. RuterbusCh, Multiple Aperture Three-Dimensional Image Construction Utilizing Fringe Modulated Speckle Patterns, Opt. Lett. 7 (1982), 599-601.

63. J. A. Gilbert, T. D. Dudderar, J. H. Bennewitz, The Application of Fibre Optics to Remote Speckle Metrology Using Incoherent Light, Opt. Lasers Eng. 3 (1982), 183-196.

64. A. Glindemann, Diplomarbeit, T. U. Braunschweig (Germany), 1982.

65. J. W. Goodman, J. Electr. Electronic Eng. (Australia), 2 (1982), 140.

66. H. Goslowsky, I. Menzel, Some Results from Experimental Speckle Interferometry, Optik 60 (1982), 149-159.

67. A. H. Greenaway, Diffraction Limited Pictures from Single TurbulenceDegraded Images in Astronomy, Opt. Commun. 42 (1982), 157-161.

68. C. P. Grover, R. Tremblay, Real-Time Image Subtraction Using Complementary Photographic Diffusers, Appl. Opt. 21 (1982), 2666-68L.

69. C. P. Grover, R. Tremblay, Imaging with Photographic Diffusers, Appl. Opt. 21 (1982), 4500-4504.

70. K. K. Gupta, R. D. Bahuguna, K. Singh, The Contrast of Partially Developed Speckles in the Image Plane: Point Scatterer Model, J. Opt. (India) 11 (1982), 29-35.

71. J. H. Hannay, Intensity Fluctuations Beyond a One-Dimensional Random Refracting Screen in the Short-Wavelength Limit, Opt.. Acta 29 (1982), 1631-1649.

72. A. Hayashi, Y. Kitagawa, Laser Speckle Velocimeter Utilizing Optical Fibers, Opt. Commun. 43 (1982), 161-163. 
73. E. K. Hege, E. N. Hubbard, P. A. Strittmatter, W. J. Cocke, The Steward Observatory Speckle Interferometry System, Opt. Acta 29 (1982), 701-715.

74. E. K. Hege, E. N. Hubbard, J. D. Drummond, P. A. Strittmatter, S. P. Worden, T. LAUer, Speckle Interferometric Observations of Pluto and Charon, Icarus 50 (1982), 72-81.

75. E. K. Hege, E. N. Hubbard, W. J. Cocke, P. A. Strittmatter, S. P. Worden, R. R. RadicK, [in] Internat. Astron. Union Colloquium, Proc. '62, Flagstaff, 1981, [Ed.] R. S. Harrington, Bull. Lowell Observ., 1982.

76. E. K. Hege, et al., Speckle Interferometry with the Multiple Mirror Telescope, J. Opt. Soc. Am. 72 (1982), 1759A.

77. K. Hinsch, K. BRokopf, Real-Time Speckle Correlation by Holographic Matched Filtering for Measurement of Microstructure Changes and Motion Tracking, Opt. Lett. 7 (1982), 51-53.

78. J. HoloubeK, Method of Measuring the Surface Roughness Based on the Laser Speckle Analysis, Jemna Mech. Opt. (1982), 5-9.

79. T. HoriUCHI, Y. TOMITA, R. KAMNEL, Surface Roughness Measurement with Speckle Intensity Distribution Detected Using a Linear Image Sensor, Jap. J. Appl. Phys. Lett. 21 (1982), L743-45.

80. A. M. J. HuISER, A Procedure to Correct the Images of Astronomical Objects for the Distortion Due to Atmospheric Turbulence, Opt. Commun. 42 (1982), 226.

81. Y. Y. Hung, Shearography: A New Optical Method for Strain Measurement and Nondestructive Testing, Opt. Eng. 21 (1982), 391-395.

82. A. P. M. Hurden, Vibration Mode Analysis Using Electronic Speckle Pattern Interferometry, Opt. Laser Tech. 14 (1982), 21-25.

83. M. ImaI, et al., Scattering Pattern Measurements and Analysis of Sputtered Glass Optical Waveguides for Integrated Optics, IEEE J. Quant. Electron. QE-18 (1982), 789.

84. M. Imai, K. Iтон, Y. Ohtsuka, Measurements of Complex Degree of Spatial Coherence at the End Face of an Optical Fiber, Opt. Commun. 42 (1982), 97-100.

85. К. Ітон, Y. ОнтsuKa, Interferometric Image Reconstruction through the Turbulent Atmosphere, Appl. Opt. 21 (1982), 4239.

86. T. Imai, N. TakaI, T. Asakura, Dynamic Statistical Properties of Laser Speckle Produced by a Moving Diffuse Object under Illumination of a Gaussian Beam, J. Opt. Soc. Am. 72 (1982), 460-467.

87. T. Imai, N. Takai, T. Asakura, Statistical Properties of the Dynamic Dichromatic Laser Speckle, Opt. Commun. 44 (1982), 13-18.

88. E. JAKEMAN, Scattering by a Corrugated Random Surface with Fractal Slope, J. Phys. A: Math. Gen. 15 (1982), L55-L59.

89. E. JaKemAn, B. J. HoENDERS, Scattering by a Random Surface of Rectangular Grooves, Opt. Acta 29 (1982), 1587-1598.

90. E. Jakeman, Fresnel Scattering by a Corrugated Random Surface with Fractal Slope, J. Opt. Soc. Am. 72 (1982), 1034-1041.

91. B. JeAn, Y. S. Lu, M. L. Roblin, Etude du centrage d'un element optiques sur 
un axe rotation par photographie "Speckle", Opt. Commun. 42 (1982), 315-319.

92. R. E. JENSEN, Effect of Speckle on Tracking with Optical Heterodyne Detectors, J. Opt. Soc. Am. 72 (1982), 1744A.

93. R. JONES, New Developments in the Design and Application of Electronic Speckle Pattern Interferometers, [in] Electro-Optics/Laser International, Brighton (UK) 1982, [Ed.] H. Jerrard, Butterworths 1982.

94. V. V. K. KaRPPINEN, Virtual Fringe Analysis Method in Time-Average Defocused Speckle Photography, Opt. Eng. 21 (1982), 60-62.

95. Y. Kawagoe, N. TakaI, T. Asakura, Speckle Reduction by a Rotating Aperture at the Fourier Transform Plane, Opt. Lasers Eng. 3 (1982), 197-218.

96. S. Komatsu, T. Morioka, H. Ohzu, Evaluation of Optical Systems Using Dynamic Laser Speckles, J. Opt. Soc. Am. 72 (1982), 1743A.

97. R. Krishnamurthy, R. S. Sirohi, M. P. KothiYAL, Speckle Shear Interferometry Using a Split Lens, J. Opt. (India) 11 (1982), 9-15.

98. R. Krishnamurthy, R. S. Sirohi, M. P. Kothiyal, Speckle Shearing Interferometry; A New Method, Appl. Opt. 21 (1982), 2265-66L.

99. R. Krishnamurthy, R. S. Sirohi, M. P. Kothiyal, Detection of Defects in Plates and Diaphragms Using a Split-Lens Speckle-Shearing Interferometer, NDT International Dec. (1982), 329-333.

100. D. T. Kuan, A. A. Sawchuk, T. C. Strand, P. Chavel, Adaptive Restoration of Images with Speckle, SPIE Proc. 359 (1982), 28-38.

101. A. LabeYrIE, Stellar Interferometry: A Widening Frontier, Sky Telesc. 63 (1982), 334-338.

102. A. LabeYrie et al., Coherent Arrays of Separate Optical Telescopes in Space Project TRIO, [in] Proc. Confer. on Very Long Baseline Interferometry Techniques, Toulouse (France) Sept. 1982.

103. M. H. LeE, J. F. Holmes, Higher Order Mode Variance and Covariance of the Intensity for a Speckle Field Propagating through Turbulence, Opt. Soc. Am. Mtg. Oct. 1982.

104. K. Leonhardt, H. J. Tiziani, Removing Ambiguities in Surface Roughness Measurement, Opt. Acta 29 (1982), 493-499.

105. R. A. Lessard, R. Tremblay, C. P. Grover, No Slit Type Rainbow Hologram; Application in Interferometry, Opt. Soc. Am. Mtg. Oct. 1982.

106. B. M. Levine, J. C. DainTy, Measurement of non-Gaussian Speckle from Diffusers of Known Statistics, J. Opt. Soc. Am. 72 (1982), 1743A.

107. O. J. LoKBERG, Speckle Techniques for Use in Biology and Medicine, [in] Optics in Biomedical Sciences, [Eds.] G. von Bally and P. Greguss, Springer-Verlag, 1982, pp. 144-153.

108. O. J. Lokberg, P. Neiswander, Biomedical Applications of ESPI, [in] Optics in Biomedical Sciences, [Eds.] G. von Bally and P. Greguss, Springer-Verlag, 1982, pp. 154-157.

109. J. J. Lunazzi, M. Muramatsu, Advantages of a Speckle Correlation Derivative Technique, J. Opt. Soc. Am. 72 (1982), 1744A.

110. P. A. Mangin, F. L. Thurstone, O. T. von Ramm, Anomalous Quantization 
Error Lobes in Phased Array Images, [in] Acoustical Imaging, Vol. 11, [Ed.] J. P. Powers, Plenum 1982, pp. 491-503.

111. P. A. Magnin, O. T. von Ramm, F. L. Thurstone, Frequency Compounding for Speckle Contrast Reduction in Phased Array Images, Ultrasonic Imaging 4 (1982), 267-281.

112. A. K. Majumdar, H. Gamo, Statistical Measurements of Irradiance Fluctuations of a Multipass Laser Beam Propagated through Laboratory-Simulated Atmospheric Turbulence, Appl. Opt. 21 (1982), 2229-2234.

113. C. Martin, C. Sieger, Application of Rainbow Holography for Speckle Reduction in Tympanic Membrane Interferometry, [in] Optics in Biomedical Sciences, [Eds.] G. von Bally and P. Greguss, Springer-Verlag, 1982, pp. 121-125.

114. G. Mas, M. Alkoussa, D. Dupuis, Main Mathematical Relationships Used in Laser Speckle, J. Opt. (Paris) 13 (1982), 155-158.

115. H. A. MCAlister, W. J. HARTKOPF, Speckle Interferometry of the Spectroscopic Binary 94 Aquarii A, Publ. Astron. Soc. Pac. 94 (1982), 832-834.

116. H. A. McAlister, H. L. Marcus, Development of a Dual Microchannel Plate Intensifier Charge Coupled Device Speckle Camera, Proc. SPIE 331 (1982).

117. D. W. MCCARTHY et al., Infrared Speckle Interferometry of the Nucleus of NGC 1068, Astrophys. J. 257 (1982), L7-L11.

118. J. Meaburn, et al., Speckle Observations of the Nucleus of NGC 1068, Nature 296 (1982), 331-334.

119. P. C. Mehta, R. Hradayanath, Fourier Plane Analysis of Smoothed Blanks for Assessment as Focal Plane Components in Electro-Optical Systems, J. Opt. Soc. Am. 72 (1982), 1737A.

120. E. R. Mendez, Speckle in Confocal Scanning Transmission Optical Microscopes, Opt. Commun. 43 (1982), 318-322.

121. E. R. MendeZ, Speckle in Confocal Scanning Optical Microscopes, [in] Max Born Centenary Conference, Edinburgh (Scotland), 1982.

122. N. Menyuk, D. K. Killinger, C. R. Menyuk, Limitations of Signal Averaging Due to Temporal Correlation in Laser Remote Sensing Measurements, Appl. Opt. 21 (1982), 3377-3383.

123. R. Meynart, Convective Flow Field Measurement by Speckle Velocimetry, Rev. Phys. Appl. 17 (1982), 301-305.

124. R. Meynart, Digital Image Processing for Speckle Flow Velocimetry, Rev. Sci. Instrum. 53 (1982), 110-111.

125. J. Montilla, R. HeRnandez, Colour Photography by Speckle Interferometry in White Light, Opt. Acta 29 (1982), 843-846.

126. B. L. Morgan, et al., Observation of Binary Stars by Speckle Interferometry liI, Mon. Not. R. Astron. Soc. 198 (1982), 817-825.

127. G.-G. MU, Z.-Q. WANG, F.-X. WU, N.-Y. ZhANG, White Light Stereoprojection with Modulated Speckle Encoding, Opt. Soc. Am. Mtg. Oct. 1982.

128. K. Nakagawa, N. Nagamatsu, T. Asakura, Y. Shindo, An Effect on the Extended Detecting Aperture on the Contrast of Monochromatic and White Light Speckles, J. Opt. (Paris) 13 (1982), 147-153. 
129. Y. Nakayama, M. Kato, Linear Recording of Fourier Transform Holograms Using a Pseudo-Random Diffuser, Appl. Opt. 21 (1982), 1410-1418.

130. M. Nieto-VesPerinas, Depolarization of Electromagnetic Waves Scattered from Slightly Rough Random Surfaces: A Study by Means of the Extinction Theorem, J. Opt. Soc. Am. 72 (1982), 539-547.

131. M. Nieto-VeSPERINAS, Radiometry of Rough Surfaces, Opt. Acta 29 (1982), 961-971.

132. K. A. O'Donnell, Correlation of Time Varying Speckle Near the Focal Plane, J. Opt. Soc. Am. 72 (1982), 191-197.

133. K. A. O’Donnell, Speckle Statistics of Doubly Scattered Light, J. Opt. Soc. Am. 72 (1982), 1743A.

134. K. A. O'Donnell, Speckle Statistics of Doubly Scattered Light, J. Opt. Soc. Am. 72 (1982), 1459-1463.

135. J. Онтsubo, Exact Solution of the Zero-Crossing Rute of a Differentiated Speckle Pattern, Opt. Commun. 42 (1982), 13-18.

136. J. Oнtsubo, Non-Gaussian Speckle: A Computer Simulation, Appl. Opt. 21 (1982), 4167-4175.

137. J. Онтsubo, Statistical Properties of Differentiated Partially Developed Speckle Patterns, J. Opt. Soc. Am. 72 (1982), 1249-1252.

138. K. Ouchi, Imagery of Ocean Waves by Synthetic Aperture Radar, Appl. Phys. B29 (1982), 1-11.

139. K. OuchI, Effect of Random Motion on Synthetic Aperture Radar Imagery, Opt. Quant. Electron. 14 (1982), 263-275.

140. C. Papaliolis, L. Mertz, New Two-Dimensional Photon Camera, SPIE Proc. 331 (1982), 360-364.

141. D. L. Parker, T. A. Pryor, Analysis of B-Scan Speckle Reduction by Resolution Limited Filtering, Ultrasonic Imaging 4 (1982), 108-125.

142. H. M. Pedersen, Intensity Correlation Metrology: A Comparative Study, Opt. Acta 29 (1982), 105-118.

143. K. Petermann, G. Arnold, Noise and Distribution Characteristics of Semiconductor Lasers in Optical Fiber Communication Systems, IEEE J. Quant. Electron. QE-18 (1982), 543-555.

144. R. Petrov, S. Kadiri, F. Martin, G. Ricort, C. Aime, Application de l'analyse interspectrale à la speckle interferometrie, J. Opt. (Paris) 13 (1982), 331-337.

145. R. L. Phillips, L. C. Andrews, Universal Statistical Model for Irradiance Fluctuations in a Turbulent Medium, J. Opt. Soc. Am. 72 (1982), 864-870.

146. K. PietzSCH, Correlation Function of General Correlated Scattering Objects, Optik 60 (1982) 449-454.

147. K. Pietzsch, On the Reconstruction of Image Plane Holograms with Scattering Properties, Optik 62 (1982), 181-187.

148. K. PietzSCH, Reconstruction of Scattering Image Plane Holograms in an Interferometer, Optik 62 (1982), 263-280.

149. J. Politch, Real-Time Imaging and Strain Distribution of an Angularly Vibrating Diffused Plate, Opt. Acta 29 (1982), 485. 
150. H. J. Rabal, E. E. Sicre, N. Bolognini, M. Garavaglia, Pseudocoloring Method for 3-D Contouring, J. Opt. (Paris) 13 (1982), 257-262.

151. V. S. Rao Gudimetla, J. F. Holmes, Covariance of the Received Intensity for a Polychromatic Speckle Pattern after Propagation through Turbulence, Opt. Soc. Am. Mtg., Oct. 1982.

152. V. S. Rao Gudimetla, J. F. Holmes, P. A. Pincus, Time Delayed Covariance of the Received Intensity for a Target Generated Laser-Speckle Pattern in the Turbulent Atmosphere, Opt. Soc. Am. Mtg., Oct. 1982.

153. V. S. Rao Gudimetla, J. F. Holmes, Probability Density Function of the Intensity for a Laser Generated Speckle Field after Propagation through the Turbulent Atmosphere, J. Opt. Soc. Am. 72 (1982), 1213-1218.

154. P. K. RASTOGI, P. JACQUOT, Speckle Metrology Techniques: A Parametric Examination of Observed Fringes, Opt. Eng. 21 (1982), 411-421.

155. G. Ricort, J. Borgnino, C. Aime, A Comparison between Estimations of Fried's Parameter $r$ Simultaneously Obtained by Measurements of Solar Granulation Contrast and of the Variance of Angle-of-Arrival Fluctuations. Solar Physics 75 (1982), 377-394.

156. F. Roddier, J. M. Gilli, J. Vernin, On the Isoplanatic Patch Size in Stellar Speckle Interferometry, J. Opt. (Paris) 13 (1982), 63-70.

157. F. Roddier, J. M. Gilli, G. Lund, On the Origin of Speckle Boiling and its Effects in Stellar Speckle Interferometry, J. Opt. (Paris) 13 (1982), 263-271.

158. P. H. RuterbusCh, J. A. TOME, F. T. S. YU, Multiplexed Speckle and Holographic Interferometry with Color Encoding and White Light Processing, J. Opt. Soc. Am. 72 (1982), 1762A.

159. P. H. RuterbuSCH, F. T. S. Yu, Color Image Retrieval from Incoherent Speckles with White-Light Processing, Opt. Eng. 21 (1982), 798-799.

160. B. E. A. SAleH, Optical Information Processing and the Human Visual System, [in] Applications of Optical Fourier Transforms, [Ed.] H. Stark, Academic, 1982.

161. K. Schatzel, G. Parry, Real-Time Moire Measurement of Phase Gradient, Opt. Acta 29 (1982), 1441-1445.

162. C. ShAKHER, Laser Speckle Photography for NDT of Diaphragms, Appl. Opt. 21 (1982), 367.

163. D. K. Sharma, R. S. Sirohi, M. P. Kothiyal, Extraction of Inplane Displacement from Sandwich Hologram Using Speckle Photography, Opt. Commun. 43 (1982), 18-20.

164. D. P. Shattuck, O. T. von Ramm, Compound Scanning with a Phased Array, Ultrasonic Imaging 4 (1982), 93-107.

165. P. F. STEEGER, A. F. FerCHER, Experimental Investigation of the First Order Statistics of Stoke Parameters in Speckle Field, Opt. Acta 29 (1982), 1395-1400.

166. P. N. Swanson, J. B. BreckinRidge, S. Gulkis, J. Kuiper, M. KiYa, SPIE Proc. 332 (1982), 151.

167. N. Takai, T. Asakura, Properties of the Dynamic Speckle Detected by a Multiple Aperture, J. Opt. (Japan) 11 (1982), 291 (63)-298 (70). 
168. H. J. TIZIANI, Real-Time Metrology with BSO Crystals, Opt. Acta 29 (1982), 463-470.

169. B. M. Tsai, C. S. Gardner, Remote Sensing of Sea State Using Laser Altimeters, Appl. Opt. 21 (1982), 3932-3940.

170. M. TUR, et al., When is Speckle Noise Multiplicative? Appl. Opt. 21 (1982), $1157-1158$.

171. H. Uozato, J. Fukuhara, M. Saishin, S. NakaO, Speckle Pattern Simulator for Visual Evoked Potentials, [in] Optics in Biomedical Sciences, [Eds.] G. von Bally and P. Greguss, Springer-Verlag, 1982, pp. 237-242.

172. H. Uozato, H. Itani, T. Matsuda, M. Saishin, S. Nakao, J. Okada, K. Iwata, R. NAGATA, Measurement of Interior Displacement of the Human Crystalline Lens by Using Speckle Pattern, [in] Optics in Biomedical Science, [Eds.] G. von Bally and P. Greguss, Springer-Verlag, 1982, pp. 162-166.

173. E. D. Vanidhis, J. Spyridelis, An Image Multiplexing Method through Internal Modulation of Speckle Patterns, Optik 61 (1982), 195-208.

174. C. S. Vikram, Simple Approach to Process Speckle Photography Data, Opt. Lett. 7 (1982), 374-375.

175. C. S. Vikram, Error in Speckle Photography of Lateral Sinusoidal Vibrations: A Simple Analytical Solution, Appl. Opt. 21 (1982), 1710-1712.

176. C. S. VIKRAM, K. VeDAM, Real-Time Interferometry of Rough Surfaces by Observing Fringes inside Laser Speckles, J. Opt. Soc. Am. 72 (1982), 1744A.

177. N. A. Voishyillo, N. I. ShCherbakova, Parameters of the "Speckle Patterns" Formed when Coherent Radiation Passes through Opal Glasses, Sov. J. Opt. Tech. 49 (1982), 413-415.

178. R. E. WAGNeR, C. R. SANDAhL, Interference Effects in Optical Fiber Connectors, Appl. Opt. 21 (1982), 1381.

179. J. G. WalKer, E. JaKemAN, Non-Gaussian Light Scattering by a Ruffled Water Surface, Opt. Acta 29 (1982), 313-324.

180. J. G. WALKer, Computer Simulation of a Method for Object Reconstruction from Stellar Speckle Interferometry Data, Appl. Opt. 21 (1982), 3132-3137.

181. C. WYKes, Use of Electronic Speckle Pattern Interferometry (ESPI) in the Measurement of Static and Dynamic Surface Displacements, Opt. Eng. 21 (1982), 400-406.

182. I. Yamaguchi, Simplified Laser-Speckle Strain Gauge, Opt. Eng. 21 (1982), 436-440.

183. I. Yamaguchi, S-i Mizuno, H. Saito, Development of an Automatic Analyser of Speckle Photographs, Kogaku (Jap. J. Opt.) 11 (1982).

184. T. Yoshimura, H. Fukumaru, N. WaKabayashi, Single-Interval Statistics of non-Gaussian Light in the Presence of Number Fluctuations, J. Opt. Soc. Am. 72 (1982), 780-786.

185. F. T. S. YU, P. H. RuterbusCh, Color Image Retrieval from Incoherent Speckles with White-Light Processing, Opt. Eng. 21 (1982), 798-799.

186. F. T. S. Yu, P. H. RuterbusCh, Color Image Retrieval from Coherent Speckles by White Light Processing, Appl. Opt. 21 (1982), 2300-2301. 
187. F. T. S. YU, Optical Information Processing, Wiley, 1982.

188. S. YU-Dong, J. W. K. HuANG, Speckle Interferometry for Measuring Small Rotation, Am. J. Phys. 50 (1982), 664-666. 